\title{
Approach to the Management of the Pregnant Inflammatory Bowel Disease Patient: Successful Outcome
}

\author{
Flavio M. Habal \\ University Health Network \\ University Of Toronto \\ Canada
}

\section{Introduction}

Inflammatory bowel disease (IBD) encompasses Crohn's disease (CD) and ulcerative colitis (UC) and it affect young adults in their reproductive years (Andres \& Friedman, 1999).

Approximately $25 \%$ of these patients will conceive after the diagnosis is made. Many women with IBD raise concerns related to the effects of both the disease and medical therapy on fertility, pregnancy and foetal outcomes. On the basis of prospective and registry data, it is known that women with IBD have a higher risk of low-birth-weight deliveries and pre-term deliveries (Cornish J, 2007). With the exception of patients who have had previous pelvic surgery, the majority of these patients are able to conceive, have a normal pregnancy and a good foetal outcome. Maintaining remission, with drug therapy, prior to conception and during pregnancy is of prime importance. Control of disease activity before conception and during pregnancy is critical to optimize both maternal and fetal health (Mountfield, 2010). Normal maternal weight gain during pregnancy appears to protect against adverse outcome. The majority of drugs used in IBD appear to be safe and their benefit appears to outweigh the risk of disease exacerbation and poor foetal outcome. The newer biologic anti TNF alpha drugs appear to be safe during pregnancy.

Although there are reports of some traces of drugs in breast milk in women taking medications no major undue complication has been reported.

Treatment of IBD patients who are contemplating conception should be tailored to each patient, taking into accounts the patient wishes and concerns. The patient should be followed by a multidisciplinary team including the family physician, the gastroenterologist and the obstetrician.

\section{Preconception advice and counselling}

Preconception care aims to ensure the optimal physical and mental well-being of women and their partners at the onset of and during early pregnancy, to increase the likelihood of normal pregnancy and the delivery of a healthy infant. Pre pregnancy counselling should be an integral part of IBD consultation. Patient understanding of the disease and its changes during pregnancy and breastfeeding is vital for a successful outcome. In a recent 
abstract from England the authors showed that there was a lack of knowledge and understanding in the women of reproductive age about their disease, medication and effects of these on pregnancy. It is important to discuss the issues related to pregnancy and conception either at diagnosis or when medication is initially prescribed. In our experience some pregnant women tend to stop their medication in fear of the side effect of the drugs on the developing foetus, with an inherent risk of disease flare up. A questionnaire study by Mountfield et al found that a large proportion of subjects (84\%) reported concerns that IBD medications would harm their pregnancy, whereas only $19 \%$ women reported concerns about the effect of active IBD on pregnancy. The author reported that patients with active disease had higher risks of adverse outcome with a better outcome if they are in remission (Mountfield, 2010).

It is estimated that more than $50 \%$ of pregnancies are not planned hence as soon as the diagnosis is made this issue should be brought up. See table 1, for general pre-pregnancy recommendations.

Folic acid is an important vitamin that should be taken prior to conception since neural tube defect occurs as soon as conception is discovered. It is interesting in the British abstract only 43 women $(65.15 \%)$ knew the beneficial effect of folic acid pre-conception and during the first trimester of pregnancy (Chakrabarty \& Poullis, 2011).

The patient, her partner and her physician should discuss the possibility of disease exacerbation during pregnancy while off treatment and the necessary courses of action in such an event. Treatment choices depend on individual preference, disease severity and potential for drug toxicity. Risks and benefits of maintenance therapies during pregnancy with the best available evidence should be addressed. In addition, breastfeeding should be presented as a favourable option since it confers numerous benefits to both mother and child. The likelihood of medication secretion in breast milk and impact on foetal wellbeing should be approached and encouraged.

\begin{tabular}{|l|}
\hline \multicolumn{1}{|c|}{ General advice pre pregnancy } \\
\hline 1. Discuss potential pregnancy outcome, breast feeding, and drug therapy \\
\hline 2. Diet and nutrition \\
\hline 3. Folic acid supplementation $5 \mathrm{mg}$ daily \\
\hline 3. Stop smoking \\
\hline 4. Decrease alcohol intake \\
\hline 5. Establish a record of vaccination and update \\
\hline
\end{tabular}

Table 1.

\section{Dietary supplementation and nutritional therapy}

Nutritional therapy: The average weight gain during pregnancy is 11-16 kg. Early nutritional intervention is indicated in pregnant women with active IBD who may not be gaining weight. Enteral feeding has been anecdotally shown to be associated with normal pregnancy outcome (Teahon, 1991) and total parenteral nutrition (TPN) may be required in very sick IBD patients. 
TPN proved to be helpful and lifesaving in malnourished pregnant women and promoted foetal growth, as shown by the longitudinal ultrasonographic evaluations (Caruso, 1998).

\section{Folic acid, calcium and vitamin D}

Folic acid supplementation is recommended for all pregnant women. Women with IBD may have folic acid deficiency or be taking medications that interfere with folic acid metabolism such as Sulfasalazine (Alstead, 2002). Certain patients with Cohn's disease are on low residue diet and may be folate deficient. Thus, pregnant women with IBD should be encouraged to take $5 \mathrm{mg}$ of folic acid per day instead of $1 \mathrm{mg} / \mathrm{d}$ as recommended for the general population. Also, patients with IBD on steroid therapy should be encouraged to take calcium and vitamin D supplementation to prevent bone loss.

\section{Alcohol}

Heavy drinking throughout pregnancy can result in what is known as foetal alcohol syndrome. Patients contemplating pregnancy should be educated about the adverse effects of alcohol. Foetal Alcohol Syndrome (FAS) is a pattern of mental and physical defects clinically defined by growth deficiency, central nervous system damage and dysfunction, and a unique cluster of facial abnormalities. on foetal development. Prenatal alcohol exposure can also cause less pronounced mental, learning and behavioural disabilities in the child, commonly termed as Foetal Alcohol Spectrum Disorders (FASDs) (Davies \& Bledsoe, 2005).

\section{Smoking}

Smoking increases the risk of developing CD and worsens its course, increasing the need for steroids, immunosuppressants and re-operations. It appears that smoking cessation improves CD and aggravates ulcerative colitis (Lakatos P Let al, 2007).

Tobacco smoking during pregnancy has been associated with placenta previa, placental abruption, premature rupture of membranes (Shah \& Bracken, 2000; Mercer, 2008). It can result in small foetal size at 10-19 weeks and may result in early premature birth, low birth weight, and poor foetal outcome. Smoking cessation should be encouraged in the patient prior to, during and after pregnancy.

\section{Heredity}

Genetic factors appear to play a role in the pathogenesis of Crohn's disease (CD) and ulcerative colitis (UC) (Thompson $\mathrm{N}$ et al. 1996).

In association with environmental triggers, heredity increases the risk of developing IBD; however, studies of twins also indicate the involvement of multiple factors (Orholm $\mathrm{M}$, 2000; Tysk C et al 1988). Offspring of patients with IBD are two to 13 times more likely to develop IBD than the general population. The risk of an infant developing IBD is $8 \%$ to $11 \%$ if one parent has IBD and $20 \%$ to $35 \%$ if both parents have the disease. Data suggest, however, that the risk is decreased in breastfed infants (Yang H et al 1983).

In the general population, approximately $4 \%$ of babies born every year have congenital abnormalities, an outcome similar to what is seen in retrospective studies of women whose IBD is treated during their pregnancy. Studies that report prematurity and small-for- 
gestational-age infants did not document maternal smoking, alcohol consumption, disease status and medication use.

\section{Effect of IBD on fertility, pregnancy and foetal outcomes}

\subsection{IBD and fertility}

Infertility rates in women with inactive $\mathrm{CD}$ appear to be similar to those of the general population ( $8 \%$ to $10 \%$ ) (Khosla et al 1984).

Active disease decreases fertility, possibly as a result of decrease libido, fatigue and concerns regarding the disease. Other factors may be caused by inflammation or adhesions in the fallopian tubes or ovaries, and may cause painful intercourse (Steinlauf \& Present DH 2004). Some women choose not to bear children secondary to fear of pregnancy (Marri, 2007) and the risk of inheritance of the disease and the possible harmful effect of drug therapy. Patient education preconception may alleviate this fear and may lead to successful pregnancy.

Women who have undergone ileal pouch-anal anastomosis are less fertile. In a recent metaanalysis of ileal pouch-anal anastomosis (IPPPA) resulted in a threefold increased risk of infertility as opposed to those treated medically (Waljee J et al 2006).

Some of the evidence suggests that extensive pelvic surgery and rectal resection with the creation of J pouch lead to scarring, adhesions and tubal infertility (Arkuran \& McComb, 2000; Oresland et al, 1994).

Despite these suggestions it appears that the majority of these patients can still conceive with IVF (Kwan \& Mahadevan, 2010). In patients with active Crohn's disease there appear to be decreased fertility, which can be restored upon induction of remission (Baiocco \& Korelitz, 1984).

It is recommended that female patients who are planning to conceive and require colectomy for acute ulcerative not undergo IPPPA and instead undergo ileostomy and rectal sparing. IPPPA should then be performed after conception. Despite this recommendation, there is no data as yet to support such an approach (Janneke, 2010). Patients, who undergo IPPPA, are more likely to have a Caesarean section following RPC (Cornish, 2011).

\subsection{IBD and pregnancy outcomes}

Due to the lack of prospective studies clinical outcomes in IBD and pregnancy has been controversial with data showing poor outcome and others showing no effect. Some of these reviews or meta-analysis did not take into account some factors such as drug use by the patients, population age, smoking and alcohol and duration of disease (Dominitz et al, 2002; Fonager et al 1992). Similarly the reviews are variable between ulcerative colitis and Crohn's disease.

In 2007 Cornish et al published a meta-analysis on the influence of IBD on pregnancy. The analysis reviewed 12 studies that met specific inclusion criteria and reported the outcomes of interest. The studies included 1952 women with CD, 1113 with UC and 320,531 controls. For women with IBD, the analysis found a 1.87-fold increase in premature births (less than 37 weeks; $\mathrm{P}<0.001$ ); more than double the incidence of low birth weight (LBW) (less than 2500 g; $\mathrm{P}<0.001)$; a 1.5-fold increase in caesarean section $(\mathrm{P}<0.001)$; and a 2.37 -fold increase in congenital abnormalities $(\mathrm{P}<0.001)$. The analysis was unable to determine which women had a higher risk of adverse outcomes, but the authors concluded that pregnant women with IBD should be treated as a high-risk group. There were significant limits to this study. These studies were of an observational nature which make them vulnerable to bias; the low 
incidence of adverse outcomes makes statistical precision difficult; and disease activity was not reported in relation to outcomes. In addition, increased risks of congenital abnormalities associated with 5-ASA, azathioprine and anti-TNF-alpha medications seen in a pooled analysis may be associated with the disease and not the medications. The authors also pointed out the need for a definitive study to determine optimal management and to support the development of new guidelines to assist patients and clinicians in decisionmaking (Cornish et al 2007).

In a recent publication by Raatikainen there was a lower birth weight of newborns from mothers with UC as compared to the general population ( 3317 _ s.d. 658 g vs. 3506 _ s.d. 613 g, P $=0.003 ; 3340$ _ s.d. 631 g vs. 3507 _ s.d. 613 g, P = 0.002) respectively. Newborns in the $\mathrm{CD}$ group were also smaller than those in the reference group but the difference was not statistically significant (Raatikainen et al 2011).

A Taiwanese, Asian population database from 2001-2003 study found an increase of preterm births (11.73 vs. $6.25 \% ; p=0.004)$ and LBW (12.76 vs. $5.55 \% ; p<0.001)$, controlling for maternal characteristics including age, parity and education level (Lin, 2010). In a cohort study from Northern California Kaiser population, pregnant women with IBD were more likely to have a spontaneous abortion (OR: 1.65; 95\% CI: 1.09-2.48); an adverse pregnancy outcome (stillbirth, preterm birth or SGA infant; OR: 1.54 ; 95\% CI: $1.00-2.38$ ); or a complication of labour (OR: 1.78; 95\% CI: 1.13-2.81). The study did not find a difference in the rate of congenital malformations in control versus IBD patients, either as a group or for UC and CD separately (Mahadevan et al 2007).

In a review in 1998 Subahani et al found that CD, especially active disease, is associated with decreased birth weights, preterm delivery and caesarean section (Subahani \& Hamilton, 1998). In a case-control study published by Bush comparing 116 pregnancies in patients with IBD with 56,398 controls, there were no differences in ante partum complications, including chronic hypertension, hyperemesis gravidarum, preterm labour or pre-eclampsia. Among patients with IBD, however, induction of labour ( $32 \%$ versus $24 \%$; $\mathrm{P}=0.002)$, chorioamnionitis $(7 \%$ versus $3 \% ; \mathrm{P}=0.04)$, and caesarean section ( $32 \%$ versus $22 \% ; \mathrm{P}=0.007$ ) were all more frequent. Neonatal complications, including low birth weight (LBW), very low birth weight, intrauterine growth restriction, Apgar scores and congenital anomalies, were similar in both groups. Subgroup analysis found a decreased risk of LBW associated with previous IBD surgery, quiescent disease, and CD compared with UC (Bush et al, 2004).

The most recent and only prospective study has just been published by the ECCO-Epicom study (Bertoli et al, 2011). This study from Europe was prospective case-controlled with 332 patients with IBD both Crohn's disease and Ulcerative colitis who were pregnant and were compared to non-IBD pregnant women in the general population. In this study there was no difference in live births, spontaneous or therapeutic abortions, infant death in utero, preterm deliveries and caesarean sections. There was no difference in congenital anomalies or birth weight as compared to outcome in pregnancy in the general population. The only risk that was demonstrated to be associated with congenital anomaly and preterm delivery was older age $\geq$ 35 years. Smoking was found to be a factor which increased the risk of preterm delivery.

Dejaco performed a prospective study assessing risk factors for poor pregnancy outcome in 58 patients with IBD (Dejaco, et al 2006). The authors found that active disease during pregnancy represents a significant risk factor for unfavourable birth outcome. These results support the current treatment guidelines, which state that the maintenance of remission during pregnancy is essential (Carter, et al 2004). Pregnant women should be treated as aggressively as women who are not pregnant. 


\section{Mode of delivery}

The decision to have a caesarean section should be made on purely obstetric grounds with a discussion with the gastroenterologist. In a meta-analysis in 2007, a pregnant woman with IBD was 1.5 times more likely to undergo c section $(95 \%$ CI 1.26-1.79; p<0.001) (Cornish et al, 2007). Some surgeons advise elective caesarean section to avoid risk of anal sphincter damage. Vaginal delivery and episiotomy may lead to development or worsening of perianal CD (Brandt LJ, 1995). Current indications for caesarean section are active perianal disease and presence of an ileoanal pouch. There is no absolute contraindication to vaginal delivery in pregnant patients with inactive IBD (Alexandra Ilnyckyet al, 1999).

\section{Endoscopy during pregnancy}

It is best to avoid any major investigation during pregnancy such as radiation, endoscopy or major surgery. Indications for endoscopy during pregnancy include significant or continued gastrointestinal bleeding, dysphagia, severe or (Qureshi et al, 2005) refractory nausea and vomiting or abdominal pain, and a strong suspicion of a colonic mass. It is best to postpone endoscopy to the second trimester. If endoscopy is indicated it is important to place the patient in lateral decubitus position avoid vena caval or aortic compression by the gravid uterus. This otherwise may lead to decreased uterine blood flow and foetal hypoxemia (Kemmerer, 1979).

No evidence exists that would suggest endoscopy could affect the pregnancy. Obstetrical support should be available in the event of a pregnancy-related complication, and the presence of foetal heart sounds should be confirmed before administering sedation before and after the procedure (Qureshi et al, 2005).

Endoscopy should be done with minimal sedation. Meperidine, FDA class B followed by small doses of midazolam FDA class C. (Qureshi, 2005) Benzodiazepines (D) should be avoided in the first trimester since they have been associated with congenital cleft palate and when used late in pregnancy with neurobehavioral disorders (Ornoy, 1998; Dolovich, et al 1998; Laegreid et al,1989). Propofol, FDA class B, should be administered by an anaesthetist; its safety as yet in first trimester has not been studied (Gin, 1994).

\section{Radiology}

An excellent guideline regarding pregnancy and radiation has been published by the CDC Radiation and Pregnancy: A Fact Sheet for Clinicians Prenatal Radiation Exposure: A Fact Sheet for Physicians (CDC) 2003 http://www.bt.cdc.gov/radiation/prenatalphysician.asp , and documentations could be found in: Valentin J, 2000.

In certain circumstances radiographic imaging may be needed to rule out obstruction, perforation or toxic mega colon. Investigations that expose the patient to less radiation are preferable specifically plain abdominal films rather than CT or barium studies. Ultrasound is the safest form of radiologic imaging. It can be used to assess abscess formation and can provide information on bowel wall thickness. MRI studies are also safe and have been used to diagnose terminal ileal CD during pregnancy since active disease in the mother has an adverse effect on the foetus; investigation for diagnostic and therapeutic purposes is warranted and should not be delayed. The foetal radiation dose should be estimated by 
qualified medical personnel to provide a more detailed approximation of risks to the foetus (Osei et al, 1999).

\section{Medication and therapy during pregnancy}

Aside from Methotrexate and Thalidomide most of the drugs used in IBD appear to be safe during gestation. The US FDA classification of drugs offers a guide to the use of medications during pregnancy. The FDA categories are listed in table 2.

\begin{tabular}{|l|l|}
\hline Definition & Class \\
\hline $\begin{array}{l}\text { Controlled studies in women fail to demonstrate a risk to the foetus in the first } \\
\text { trimester (and there is no evidence of risk in later trimesters) and the possibility } \\
\text { of foetal harm appears remote }\end{array}$ & A \\
\hline $\begin{array}{l}\text { Either animal reproduction studies have not demonstrated a foetal risk, but there } \\
\text { are no controlled studies in pregnant women OR animal reproduction studies } \\
\text { have shown an adverse effect (other than decrease in fertility) that was not } \\
\text { confirmed in controlled studies in women in the first trimester (and there is no } \\
\text { evidence of risk in later trimesters) }\end{array}$ & B \\
\hline $\begin{array}{l}\text { Either studies in animals have repeated adverse effects on the foetus (teratogenic, } \\
\text { embryonic or other) and there are no controlled studies in women or studies in } \\
\text { women and animals are not available. Drugs should be given only if the potential } \\
\text { benefit justifies the potential risk to the foetus }\end{array}$ & C \\
\hline $\begin{array}{l}\text { There is positive evidence of human foetal risk but the benefits from use in } \\
\text { pregnant women may be acceptable despite the risk (e.g. if the drug is needed in } \\
\text { a life threatening situation or for a serious disease for which safer drugs cannot be } \\
\text { used or are ineffective) }\end{array}$ & D \\
\hline $\begin{array}{l}\text { Studies in animals or human beings have demonstrated foetal abnormalities OR } \\
\text { there is evidence of foetal risk based on human experience OR both, and the risk } \\
\text { of the use of the drug in pregnant women clearly outweighs any possible benefit. } \\
\text { The drug is contraindicated in women who are or may become pregnant. }\end{array}$ & X \\
\hline
\end{tabular}

Table 2. Food and drug administration (FDA) classes in pregnancy

Crohn's disease and ulcerative colitis appear to be mediated by different aspects of immune system. CD is thought to be related to the over expression of T cell helper (Th) 1 cytokines, such as TNF-alpha, which stimulate cell-mediated immunity and result in transmural inflammation of the gut (Neissner \& Volk, 1995). In contrast, UC is believed to result from a dysregulation of intestinal immunity involving the Th2 cytokine response. Increased expression of TNF-alpha, however, has been observed in patients with UC. The newer treatment modalities, with biologics, over the past decade, are to target specific inflammatory mediators such as TNFa.

There are several medications used to treat IBD. These include aminosalicylates, such as Mesalamine, and immune modulators, such as Azathioprine and Methotrexate. Other drugs include Corticosteroids which are effective in inducing remission in both $C D$ and UC but ineffective in maintenance therapy. Steroids result in side effects in the majority of patients taking the drug on a long term basis. 


\begin{tabular}{|l|l|}
\hline Medications & $\begin{array}{l}\text { FDA } \\
\text { Class }\end{array}$ \\
\hline $\begin{array}{l}\text { 5-Aminosalicylic acid* preparations (sulfasalazine, } \\
\text { mesalamine, balsalazide); metronidazole, } \\
\text { amoxicillin/clavulanic acid; infliximab; adalimumab; } \\
\text { Certolizumab }\end{array}$ & $\mathrm{B}$ \\
\hline $\begin{array}{l}\text { 5-Aminosalicylic acid preparations (Olsalazine); } \\
\text { fluoroquinolones; corticosteroids; } \\
\text { bisphosphonates;cyclosporin; tacrolimus } \\
\text { Biphosphonates }\end{array}$ & $\mathrm{C}$ \\
\hline Azathioprine; 6-MP & $\mathrm{D}$ \\
\hline Methotrexate; thalidomide & $\mathrm{X}$ \\
\hline
\end{tabular}

Table 3. Inflammatory bowel disease medications FDA classes: Summary of safety data during pregnancy* Asacol (Mesalamine) Dibutyl phthalate (DBP)

\section{P=PRECAUTIONS}

A recent study by Moskovitz et al (2004) assessed the effect of 5-ASA drugs, metronidazole, ciprofloxacin, prednisone, 6-mercaptopurine, azathioprine and cyclosporine on pregnancy outcomes in 113 IBD patients with 207 documented conceptions. The authors reviewed information obtained on smoking history, birth weight, and type of delivery. They also followed the pregnancy outcomes: spontaneous abortion, therapeutic abortion, maternal or foetal illness resulting in abortion, premature birth, healthy full-term birth, multiple births, ectopic pregnancy and congenital defects. The study also analyzed the effect of medications on pregnancy outcomes during the first trimester and at any time during the pregnancy. No significant differences were seen among groups in pregnancy outcomes. A multivariate analysis controlling for maternal age showed no negative influence of any medication on pregnancy outcomes.

\section{5-ASA compounds sulfasalazine/mesalamine/olsalazine}

Sulfasalazine has been assigned to pregnancy category B by the FDA. It was one of the earliest therapeutics used in IBD. Sulfasalazine is metabolized by intestinal bacterial flora to sulfapyridine (SP) and 5-ASA. Sulfapyridine crosses the placenta to the fetus with the foetal concentrations being approximately the same as the maternal serum concentrations. Caution should be exercised when Sulfasalazine is administered to a nursing woman. Sulphonamides are excreted in the milk. In the newborn, they compete with bilirubin for binding sites on the plasma proteins and may thus cause kernicterus.

There was no significant increase in prevalence of selected congenital abnormalities in the children of women treated with Sulfasalazine during pregnancy. A review of the medical literature covering 1,155 pregnancies in women with ulcerative colitis suggested that the 
outcome was similar to that expected in the general population (Jarnerot, 1982). Sulfapyridine acts as a competitive inhibitor of the enzyme dihydropteroate synthase in the folate metabolism; and this may lead to a deficiency of dihydrofolate and tetrahydrofolate. Patients receiving Sulfasalazine should receive folic acid supplementations.

Oligospermia and infertility have been observed in men treated with Sulfasalazine; this effect is reversed upon discontinuing the drug.

At the 2006 Digestive Disease Week in Los Angeles, USA, Mahadevan reported that the use of 5-ASA and Sulfasalazine during pregnancy was not associated with an increase in adverse outcomes. A trend toward an increased risk of congenital malformations was seen during conception and the first trimester with Sulfasalazine, but not with 5-ASA. On the contrary, an increased risk of adverse outcomes was seen in women not taking 5-ASA during the second and third trimesters, suggesting a protective effect of the medication (Mahadevan \&Corley, 2006).

In a recent meta-analysis of seven studies prior to 2007, with a total of 2200 pregnant women with IBD there was an 1.16-fold increase in congenital malformations, an 2.38-fold increase in stillbirth, an 1.14-fold increase in spontaneous abortion, an 1.35-fold increase in preterm delivery, and an 0.93-fold increase in low birth weight (Rahimi R et al 2008; Norgard et al, 2003).

Asacol is covered with an inactive enteric coating of dibutyl phthalate (DBP) that prevents the medication from degrading before it reaches the small intestine. DBP was associated with external and skeletal malformations and adverse effects on the male reproductive of rodents system. Patients who are using Asacol have 50 times higher mean urinary concentration of monobutyl phthalate, the main DBP metabolite, than the mean for nonusers $(2,257$ microg/L vs. 46 microg/L; p < 0.0001) (Hernández-Díaz et al 2009). These results raise concern about potential human health risks, particularly pregnant women and children. Although this has not been shown in any human study, Asacol should be used during pregnancy only if the potential benefit justifies the potential risk to the fetus.FDA 2010 Safety Labelling Changes Approved By FDA Center for Drug Evaluation and Research (CDER) - May 2010.These patients may need to be switched to non DBP containing Mesalamine .

\begin{tabular}{|l|l|l|}
\hline Contraindicated & Limited data, potential toxicity & Safe \\
\hline Thalidomide & Metronidazole & 5-ASA preparations \\
\hline Methotrexate & Fluoroquinolones & (sulfasalazine/mesalamine) \\
\hline Cyclosporine & Bisphosphonates & Amoxacillin/clavulanic \\
\hline Tacolimus (FK506) & Azathioprine & Acid \\
\hline & 6-Mercaptopurine (6-MP) & Corticosteroids \\
\hline & Adalimumab & \\
\hline & Infliximab & \\
\hline
\end{tabular}

Table 4. Breastfeeding safety of medications used to treat IBD

\section{Immune modulators}

\subsection{Azathioprine/6 mercaptopurine}

6-mercaptopurine $(6 \mathrm{MP})$ and its prodrug azathioprine (AZA) are pregnancy category D drugs. These have been proven to be effective in the treatment of steroid-dependent or resistant IBD Crohn's disease (CD) and ulcerative colitis (Gisbert et al, 2009). These drugs 
are used as immunosuppressive therapies in autoimmune diseases, transplant patients and in leukemia. Azathioprine and 6-mercaptopurine are purine analogues that interfere with the synthesis of adenine and guanine ribonucleosides. These ribonucleosides are important precursors of DNA and RNA and hence act on rapidly producing cells. Following oral intake of AZA $47 \%$ of the drug is available to the systemic circulation whereas only $16 \%$ of 6-mercaptopurine is available (Zimm, et al, 1983). In animal studies, in mice after intraperitoneal administration of azathioprine, there was evidence of increased frequencies of cleft palate, open-eye, and skeletal anomalies. There was a significant decrease in thymic size. The dose given is equivalent of 4-13 times the maximum human therapeutic dose of AZA.There was no discussion regarding its effect on the immune system development, which is important for future immunity.

The safety of azathioprine in pregnancy comes from studies in transplantation and rheumatology patients (Rosenkrantz et al, 1967.; Gaudier, et al 1988).

The foetus is protected from potential teratogenic effects of azathioprine and 6-MP due to the lack in foetal liver of the enzyme inosinate phosphorylase which is necessary to convert azathioprine and 6-MP to active metabolites. Both these medications when used in small doses in clinical practice do not affect human interstitial cell function or gametogenesis (Golby, 1970; Penn, et al 1971).

\section{Should azathioprine/6 mercaptopurine be used in pregnancy?}

In a retrospective chart review and telephone recalls of some of the patients who had received 6-Mercaptopurine for IBD before or during conception, there was no statistical difference in abortion secondary to a birth defect, major congenital malformations, neoplasia, or increased infections among male or female patients taking 6-MP compared with controls $(\mathrm{RR}=0.85$ [0.47-1.55], $\mathrm{P}=0.59)$ (Francella, et al, 2003).

In a retrospective Swedish registry study reviewing patients receiving azathioprine (AZA) during pregnancy by women, the majority of whom were with inflammatory bowel disease, and the rest being with other autoimmune disorders, malignancy, and organ transplantation, the rate of congenital malformations was $6.2 \%$ in the AZA group and $4.7 \%$ among all infants born (adjusted OR: 1.42, 95\% CI: 0.98-2.04) (Cleary\& Kallen, 2009).

There was an association between early pregnancy AZA exposure and ventricular/atrial septal defects (adjusted OR: 3.18, 95\% CI: 1.45-6.04). Exposed infants were also more likely to be preterm, to weigh $<2500 \mathrm{gm}$, and to be small for gestational age compared to all infants born. The authors pointed in their article regarding the severity of the disease and its association with drug use (Cleary\& Kallen, 2009).

In a Danish registry study in women with Crohn's diseases receiving drug therapy during pregnancy the risk of preterm birth and congenital abnormalities was greater when azathioprine/mercaptopurine was prescribed as compared to women who did not used drugs. Preterm births were more prevalent among Thiopurine-exposed women (25\%) compared to the reference group (6.5\%). Congenital abnormalities were also more prevalent among azathioprine/mercaptopurine-exposed women (15.4 versus 5.7\%, adjusted relative risk, 2.9; 95\% CI, 0.9-8.9). Among Thiopurine-exposed women, the risk of preterm birth was also increased to 4.2 (95\% CI, 1.4-12.5) compared to the control group (Norgard, et al 2007). The conclusion of this study was subsequently challenged, based on bias, the disease activity of the patients and the use of confidential interval (Simpson, et al 2008). 
In a prospective, controlled, multicentre study conducted by the Tel Aviv University (Israel), 189 pregnant women on azathioprine were compared to a cohort of 230 pregnant women who did not take Azathioprine. The aim of that study was to determine risk of congenital malformation in pregnant women exposed to azathioprine and to assess the pregnancy outcome (Goldstein, et al, 2007). The rate of congenital malformations did not differ between the two groups; there were more cases noted of prematurity $(21 \%$ vs. $5 \%, P<$ $0.001)$ and low birth weight $(23 \%$ vs. $6 \%, P<0.001)$ in the azathioprine group.

The most recent ECCO consensus guidelines recommend the use of AZA/6-MP in high risk patients where the benefit outweighs the risk of relapse of the disease. The European consensus guidelines consider azathioprine to be safe and well tolerated in pregnant women with no consistent reports of abnormalities of fertility, prematurity, or congenital defects (Van Assche, et al 2010).

Based on the data published in the transplant literature, the American Gastroenterology Association, and The ECCO consensus guidelines, the recommendation is that Azathioprine /6-Mercaptopurine treatment to be continued during pregnancy (Van Assche, et al 2010). The discontinuation of therapy in pregnant women, in remission, may be more harmful (Zlatanic et al, 2003) than precipitating a flare up with more deleterious effect on the neonate ( Mahadevan U, Kane S. 2006). Although some negative outcomes in some cases of pregnancy in IBD women have been reported, the majority of case series or cohort studies have not shown an increase in congenital anomalies. Despite this recommendation, the risks and benefits of treatment must be carefully balanced by the patient in consultation with her Doctor and partner.

\section{Breast feeding: Azathioprine/6 mercaptopurine}

The majority of physicians have not recommended breast feeding of neonates while mothers are receiving thiopurines. The reason for this has been the theoretical potential risks of bone marrow suppression, susceptibility to infection, and pancreatitis in the neonate. In a prospective study in 10 women receiving AZA while breast feeding in 31 samples, there was only one woman who had a low measurable level on AZA in two samples of the breast milk. The concentrations of 6-MP was 1.2 and 7.6 nanograms $/ \mathrm{mL}$, as compared with therapeutic immunosuppressant level of 50 nanograms $/ \mathrm{mL}$ in serum. The conclusion of the authors was that there were no clinical or haematological signs of immunosuppression in any of the ten neonates and that breast feeding should not be withheld (Sau et al, 2007).

Based on the case reports and the presence of low to absent levels of Thiopurine in the breast milk of women receiving thiopurines, breast feeding can be continued. The benefits of breastfeeding outweigh the theoretical risk. A discussion with the mother explaining the risk benefit should be undertaken (Gardiner al, 2006; Christensen, et al 2008).

\section{Birth outcome in IBD fathers on immunosuppressive drugs}

Pregnant women with IBD who are on thiopurines drugs, and who are in remission should continue their medication during their pregnancy (Caprilli, et al 2006; Gisbert et al 2009; Van Assche et al, 2010). The safety of Thiopurine derivatives has been controversial in male patients exposed to thiopurines at the time of conception. In a retrospective study by Rajapakse published in 2000, there was an increase in adverse side effects. In 13 males 
exposed to Thiopurine at the time of conception, there were two congenital anomalies and two spontaneous abortions. Based on that study there was some concern about continuing the drug in male patients wishing to have children. Further publications did not confirm these findings (Francella, et al, 2003; Truel, et al 2010).

\section{Cyclosporine and inflammatory bowel disease}

Cyclosporine (CsA) is classified as FDA pregnancy category C. CsA is a selective immunosuppressive drug that has been used mainly in solid organ transplant such as liver, kidney and heart. CsA inhibits the activation of $\mathrm{T}$ cells, preventing formation of IL-2.In inflammatory bowel disease, it is mostly used to induce remission in acute ulcerative colitis non responsive to conventional therapy intravenous corticosteroids (Lichtiger et al, 1994; Cohen et al, 1999). Its use has been mostly used to delay surgery in acute ulcerative colitis. The majority of literature in cyclosporine and pregnancy has been reported in transplant publications (Nagy et al, 2003).

Most of the data regarding the use of cyclosporine in pregnancy comes from transplant patients. In a meta-analysis of 15 studies of pregnancy outcomes in 410 transplant patients receiving cyclosporine, showed no significant increase in major malformations. Congenital malformation was $4.1 \%$ which was similar to the general population receiving no drugs. (Nagy et al, 2003). 2003). Pregnant transplant patients who are stable while receiving Cyclosporine appear to have a good pregnancy and foetal outcome Nagy et al, 2003). Cyclosporine is secreted in breast milk at high concentrations. Due to its possible toxic effect on the newborn and possible immunosuppression, the American Paediatric association does not recommended breast feeding while taking the drug (Kwan et al, 2010).

\section{Corticosteroids (FDA class $\mathrm{C}$ )}

Corticosteroids are classified as pregnancy category $C$ drugs. They are given to patients via a variety of forms which include oral and topical formulations and those of parental preparations. These include prednisone, prednisolone, dexamethasone and budesonide. Corticosteroids are frequently used to induce remission in both Crohn's disease and ulcerative colitis. These drugs have not been shown to be effective in maintenance therapy although they are associated with side effects in almost $100 \%$ of patients taking these medications for a long term (Alstead \& Nelson, 2003). The foetal placenta contains the enzyme 11 $\beta$-hydroxysteroid dehydrogenase type 2 (11 $\beta$-HSD2), which catalyzes the metabolism of cortisol and corticosterone to inert 11-keto forms (cortisone, 11-dehydrocorticosterone). This placental enzymic barrier allows the maternal cortisol to be inactivated so that the majority of cortisol in the human fetal circulation at term is derived from the fetal adrenals (Murphy et al ,1974; Lopez-Bernal et al,1980; Beitens, et al 1973; Stewart et al, 1995). Dexamethasone is not inactivated by $11 \beta$-hydroxysteroid dehydrogenase hence it passes the placenta freely and thus should be avoided during conception.

Corticosteroids have been implicated in oral cleft palate when they are used in the first trimester (Bush et al, 2004; Carmichael, et al 1999; Pradat et al, 2003).

A recent nationwide health registry data study from Denmark between 1996 and 2008, looking at pregnant women receiving corticosteroids, with 832,637 live births was recently published in the Canadian Medical Association journal (CMAJ). This study did not demonstrate that pregnant women receiving corticosteroids during the first trimester were 
any more likely to have offspring with a cleft lip with or without cleft palate than mothers who did not take the drug (Anders et al, 2011). A prospective study was published by Mogadam reporting on the use of corticosteroids during pregnancy which was used with or without Sulfasalazine. In that study they followed the outcome in two hundred eighty-seven pregnancies on treatment and compared to 244 pregnant IBD on no treatment. There was no increased incidence of prematurity, spontaneous abortion, stillbirth, or developmental defects (Mogadam et al,1981).

Pregnant women with active disease during conception can be safely treated with corticosteroids to induce remission. Although gestational diabetes and hypertension may be precipitated, the benefit outweighs the risk.

\section{Budesonide}

Budesonide is an enteric coated locally acting glucocorticoid preparation which has a $\mathrm{pH}$ and time-dependent coating that enables its release into the ileum and ascending colon. It is used for the treatment of mild to moderate Crohn's disease with limited systemic bioavailability due to extensive first-pass hepatic metabolism. Budesonide has been shown to be effective for induction of remission in Crohn's disease.

In a limited study using 8 patients with Crohn's disease at a dose of 6-9 mg daily there was no evidence of foetal abnormality (Beaulieu, et al 2009).

\section{Breast feeding: Corticosteroids}

Corticosteroids are secreted in small amounts into breast milk. The maternal: foetal ratio of steroid serum concentrations depends on which steroid the patient is taking. The foetal levels are $10 \%-12 \%$ of that in maternal serum. It has been suggested that infants should be monitored for adrenal suppression if the mothers are taking a more than a daily dose of 40 mg. While breastfeeding is safe with steroid use, mothers are encouraged to defer breastfeeding until $4 \mathrm{~h}$ after taking oral dosing of steroids to reduce neonatal exposure. However, systemic effects in the infant are unlikely with doses of up to $40 \mathrm{mg}$ of prednisolone or equivalent (Ferguson et al, 2008; Blanford et al, 1977).

\section{Budesonides and Breast feeding}

Limited studies are available on budesonide in breast feeding. In a study in asthmatic nursing women on maintenance treatment with inhaled budesonide (200 or 400 microg twice daily) showed negligible systemic exposure to budesonide in breast-fed infants (Fält et al, 2007).

\section{Immunobiologic therapy, pregnancy and lactation}

Anti-TNF agents fall within the US FDA category B concerning foetal risk, because animal reproduction studies have failed to demonstrate a risk to the foetus but adequate and wellcontrolled studies of pregnant women have not been conducted.

Biological therapies targeting TNF-a have significantly improved the management of IBD refractory to conventional therapies, in steroids sparing, improvement in perianal disease and maintaining remission. It has been shown to result in mucosal healing. Data regarding their safety are scarce for the other compounds. No increased risks associated with pregnancy have been observed for Infliximab or Adalumimab, but caution in pregnancy and during breast-feeding is currently advocated. 
The role of TNF-alpha for embryonic implantation, foetal development and labour has been well studied. TNF-alpha controls arachadonic acid metabolism production through the cyclooxygenase pathway. Subsequently, TNF-alpha plays an important role in implantation and vascular permeability. TNF-alpha production is low in the first gestational trimester, but increases thereafter, reaching a peak at the onset of labour (Daher et al, 1999). These high levels have been shown to play an important role in the induction of the labour process and in delivery via augmenting uterine contractions. It has been reported that blastocyst implantation during early pregnancy may be promoted by TNF-alpha but at the same time it may mediate recurrent spontaneous abortion at a later stage of gestation. The serum levels of TNF-a and those of soluble TNFR-1 were found to be higher in women who had spontaneous early abortions (Yu et al,2005).

Anti-TNF agents include infliximab, a chimeric monoclonal IgG1 anti-TNF antibody, adalimumab, a human monoclonal IgG1 anti-TNF antibody, and etanercept, a soluble TNF receptor fusion protein linked to the Fc portion of a human IgG1. IgG1 antibody do not cross the placenta in the first trimester but cross the placenta by the late second trimester and the third trimester. Certolizumab another anti TNFa antibody, is a PEGylated Fab' fragment of humanized anti TNF alpha monoclonal antibody rather than a whole human immunoglobulin G1 (IgG1) antibody (Stephens 2006). A recent abstract on Certolizumab, reported on placental transfer. The report included 10 IBD women, with one twin delivery. There was a low level on antibodies of Certolizumab confirming the animal reports (Wolf et al, 2010; Stephens et al, 2006).

To date, there have been few comprehensive studies in IBD patients who had conceived while receiving immunobiologic therapy. Most of the publications and reports have been retrospective reviews. Roux et al (2007) reported their experience with three rheumatoid arthritis patients who became pregnant while undergoing anti-TNF-alpha therapy. Although one patient terminated her pregnancy despite no known pregnancy or foetal complications, the other two patients delivered healthy infants. Another study from the infliximab study database showed that 96 patients exposed to infliximab during pregnancy had outcomes no different than in the general population (Katz et al, 2004). In the first reported study of intentional infliximab administration for CD during pregnancy, Mahadevan et al (2005) showed, in acutely ill patients with Crohn's disease, excellent outcomes. All 10 pregnancies ended in live births and there were no congenital malformations, intrauterine growth retardation or small-for-gestational-age infants. In those ten patients, three of the infants were born prematurely and one had low birth weight (LBW).

There has not been adequate and well-controlled studies conducted in pregnant or lactating women. It has been increasingly used in autoimmune diseases such as rheumatoid arthritis, psoriatic arthritis (PsA), juvenile idiopathic arthritis (JIA) ankylosing spondylitis (AS) and in inflammatory bowel disease.

Most of the literature regarding anti-TNF-alpha therapy in pregnancy comes from studies in rheumatoid arthritis. The data have been obtained from retrospective studies, registry studies and case reports. Based on all publications no firm conclusions can be made regarding the long term safety of biologics during pregnancy. Mahadevan et al in the London position statement at the World Congress of Gastroenterogy consensus guideline (2010) considers infliximab to have a low risk and compatible with the use during conception in at least first and second trimester. 
Recently, the mother risk program in Canada published a review of 300 pregnancies in women who received anti TNF alpha during conception. The review suggested that infliximab carries low foetal risk and is compatible with use during conception and the first two trimesters of pregnancy (Djokanovic et al, 2011).

A recent observational study by the Leuven, group in Belgium, was published. They assessed pregnancy outcomes in 212 women with IBD. Pregnancy outcome was assessed in 42 pregnancies in women who received anti-TNF treatment (35 IFX, 7 ADA) and were compared with that in 23 pregnancies prior to IBD diagnosis, 78 pregnancies before start of IFX, 53 pregnancies with indirect exposure to IFX, and 56 matched pregnancies in healthy women. Their conclusion was that direct exposure to anti-TNF treatment during pregnancy was not related to a higher incidence of adverse outcomes than IBD overall (Schnitzler et al, 2011).

Vasiliauskas monitored a pregnant patient who continued on standard-dose infliximab therapy during her pregnancy and lactation. The measurement of serum infliximab in the breastfed infant was $39.5 \mu \mathrm{g} / \mathrm{mL}$ or less and the drug was not detected in the breast milk. Importantly, despite continued breast-feeding and adherence to therapy, the levels declined in the infant over the subsequent six months. They concluded that infliximab levels were likely due to placental transfer and less likely the result of breastfeeding (Vasiliauskas et al, 2006). The blood levels in the newborn were within the therapeutic range. The authors recommended that such therapy be avoided after 30 weeks gestation when possible. As of the date of this publication, no increased risk of embryotoxicity, teratogenicity or adverse pregnancy outcome has been reported in patients treated with anti-TNF therapy (Skomsvoll et al, 2007).

The majority of studies regarding breast feeding while receiving anti-TNF therapy has not demonstrated any adverse outcomes. The data, however, appear limited. In a case report publication in which serial sampling of breast milk over a one-month time period failed to detect any concentrations of infliximab. Furthermore, at a follow-up of just over two years, no developmental abnormalities were noted in the child. Ostensen et al (2004) showed that etanercept, a soluble TNF-alpha receptor fusion protein, was detected in breast milk with maximal doses noted the day following the injection. The effect on the developing immune system in the infant - if indeed the levels in breast milk are significant - remains to be seen. The European Panel on the Appropriateness of Crohn's Disease Therapy (EPACT), an international multidisciplinary panel, met recently to develop safety criteria for clinical decision-making related to the use of drugs in pregnant and nursing women with IBD. The panel was cautious about the safety of infliximab, based primarily on label (Mottet et al, 2007) recommendations, and emphasized the need for further large, randomized controlled trials.

At the present time the risk benefit should be always assessed. Pregnant women who are receiving biologics and are in remission should continue the treatment. In the case of Infliximab and Adalumimab it should be held at 32 weeks and restarted after delivery. Breast feeding is compatible with Infliximab treatment. No data so far on breast feeding with Adalumimab although the author does not discourage breast feeding in these women.

\section{Bisphosphonates (FDA Class C)}

Careful consideration should be undertaken in women of child bearing age who require biphosphonates. As with most drugs used during conception, the risk and benefits of biphosphonates should be carefully weighed in these women. 
There are several biphosphonates currently approved for use in osteoporosis including: alendronate (Fosamax $\left.{ }^{\circledR}\right)$, etidronate (Didrocal $\left.{ }^{\circledR}\right)$, risedronate (Actonel ${ }^{\circledR}$ ) and zoledronic acid (Aclasta $\left.{ }^{\circledR}\right)$.

Biphosphonates are used to treat and to prevent corticosteroids induced osteoporosis. Approximately $50 \%$ of the Biphosphonates binds to the skeleton and the rest is excreted non-metabolized by the kidneys (Papapoulos, 2008). The long-term effects of alendronate, one of the Biphosphonates, on human bone development are unknown and the half-life of alendronate is greater than 10 years. The concern with long-term biphosphonates treatment is that the drug is slowly released from maternal bone and may result in continuous lowlevel exposure to the foetus during gestation. The released bisphosphonate can cross the placenta and incorporate into foetal bone. In animal studies where biphosphonates were given to pregnant rats, the drug appears to cross the placenta, accumulate in the foetal skeleton, decrease foetal weight, decrease bone growth, and lead to protracted deliveries and neonatal deaths (Patlas et al, 1999).

\section{Summary and conclusion}

Managing a pregnant woman with inflammatory bowel disease is challenging but often rewarding. This management should include the patient and her partner, in association with the family physician, the gastroenterologist and the obstetrician. Most women with IBD, who are in remission, are as likely as women without IBD to conceive and have a normal pregnancy. These patients should be encouraged to continue the medications throughout the pregnancy and while breast feeding.

Women with ulcerative colitis who have undergone ileal pouch-anal anastomosis operation are less likely to conceive. Women with active ulcerative colitis who require colectomy, and are planning to have a family, should reconsider having a pouch surgery. They should have an ileostomy and postpone a pouch until after conceiving. With the exception of Methotrexate, most drugs used in IBD are relatively safe to administer in pregnancy and can be used while breast feeding.

The newer biologic drugs appear to be quite effective and safe during pregnancy and with breastfeeding. Since these drugs cross the placenta mostly in the third trimester they should not be administered after 32 week of gestation.

Despite all our knowledge and availability of literature the risk benefit should be always weighed. The decision of the mother should always be respected, should she decide on not taking the medications.

\section{Take home messages:}

1. Patient education is of primary importance in a successful outcome in IBD women during pregnancy.

2. IBD patients in remission have the same chance in getting pregnant as non IBD patients.

3. Pregnant IBD patients outcomes are better if patients are maintained in remission.

4. Ileoanal pouch patients have a lower rate of conception.

5. Biologics drugs appear to be safe during pregnancy and in lactation.

6. Biologic drugs, if possible, should be withheld at 32 weeks gestation

7. Breast feeding should be encouraged in women receiving most of IBD drugs. 


\section{References}

Alstead EM. Inflammatory bowel disease in pregnancy. Postgrad Med J. 2002; 78:23-26.

Alstead EM, Nelson-Piercy C. Inflammatory bowel disease in pregnancy. Gut. 2161.

Anders Hviid, Ditte Mølgaard-Nielsen. Corticosteroid use during pregnancy and risk of oro facial clefts. CMAJ, 2011,April11.

Andres PG, Friedman LS. Epidemiology and the natural course of inflammatory bowel disease. Gastroenterol. Clin. North Am. 1999;28(2):255-281, vii.

Arkuran C, McComb P. Crohn's disease and tubal infertility: the effect of adhesion formation. Clin. Exp. Obstet. Gynecol. 2000;27(1):12-13 .

Baiocco PJ, Korelitz BI. The influence of inflammatory bowel disease and its treatment on pregnancy and fetal outcome. J. Clin Gastroenterol 1984; 6: 211-16.

Beaulieu DB, Ananthakrishnan AN, Issa M, Rosenbaum L, Skaros S, Newcomer JR, Kuhlmann RS, Otterson MF, Emmons J, Knox J, Binion DG. / Budesonide induction and maintenance therapy for Crohn's disease during pregnancy. Inflamm Bowel Dis. 2009 Jan; 15(1):25-8.

Beitens, IZ, Bayard, F, Ances, IG, Kowarski, A, Migeon, CJ: The metabolic clearance rate, blood production, interconversion and transplacental passage of cortisol and cortisone in pregnancy near term. Pediatr Res 1973 7:509-519.

Bertoli A ,Pedersen N, Duricova D, et al: Pregnancy outcome in inflammatory bowel disease:prospective European case control ECCO-EpiCom study,2003-2006. Aliment Pharmacol Ther.2011:1365 (on-line publication August 2011).

Blanford AT, Murphy BE. In vitro metabolism of prednisolone, dexamethasone, betamethasone, and cortisol by the human placenta. Am J Obstet Gynecol. 1977; 127:264-267.

Brandt LJ, Estabrook SG, Reinus JF. Results of a survey to evaluate whether vaginal delivery and episiotomy lead to perineal involvement in women with Crohn's disease. Am J Gastroenterol. 1995;90:1918-1922.

Bush MC, Patel S, Lapinski RH, Stone JL. Perinatal outcomes in inflammatory bowel disease. J Matern Fetal Neonatal Med. 2004; 15:237-41.

Cantu JM, Garcia-Cruz D. Midline facial defect as a teratogenic effect of metronidazole. Birth Defects 1982; 18:85.

Caprilli R, Gassul MA, Escher JC, Moser G, et al. European evidence based consensus on the diagnosis and management of Crohn's disease: special situation. Gut 2006; 55 (suppl 1):i36-i58.

Carmichael SL, Shaw GM. Maternal corticosteroid use and risk of selected congenital anomalies. Am. J. Med. Genet. 1999; 86(3): 242-244

Carter MJ, Lobo AJ, Travis SPL., IBD Section, British Society of Gastroenterology Guidelines for the management of inflammatory bowel disease in adults. Gut. 2004; 53:V1-16.

Caruso A, De Carolis S, Sergio Ferrazzani, Carmen Trivellini, Carmen Mastromarino, Mauro Pittiruti.. Pregnancy Outcome and Total Parenteral Nutrition in Malnourished Pregnant Women Fetal Diagn Ther 1998; 13:136-140

Chakrabarty, G *, A Poullis Gut 2011; 60:A135 doi:10.1136/gut.2011.239301.287

Chatzinoff M, Guario JM, Corson SL, et al.Sulfasalazine-induced abnormal sperm penetration assay reversed on changing to 5-aminosalicylic acid enemas .Digestive Diseases and Science.1983;33:108-110.

Christensen LA, Dahlerup JF, Nielsen MJ, et al. Azathioprine treatment during lactation. Aliment Pharmacol Ther. 2008; 28: 1209-1213 
Cleary BJ, Kallen B. Early pregnancy azathioprine use and pregnancy outcomes. Birth Defects Res A Clin Mol Teratol. 2009; 85: 647-654.

Cohen RD, Stein R, Hanauer SB. Intravenous cyclosporin in ulcerative colitis: a five-year experience. Am J Gastroenterol 1999; 94:1587-1592.

Cornish J, Tan E, Singh B, Bundock H, Mortensen N, Nicholls R, Clark S, Tekkis P. Female infertility following restorative proctocolectomy. Colorectal Dis 2011;1463-1318.

Cornish J, Tan E, Teare J, et al. A meta-analysis on the influence of inflammatory bowel disease on pregnancy. Gut 2007; 56:830-837.

Davies J BJ. Prenatal alcohol and drug exposures in adoption. Pediatr Clin 2005; 52:1369-1393.

Czeizel AE, Dudas I, Paput L, Banhidy F. Prevention of Neural-Tube Defects with Periconceptional Folic Acid, Methylfolate, or Multivitamins? Ann Nutr Metab 2011; 58:263-271.

Daher S, Fonseca F, Ribeiro OG, Musatti CC, Gerbase-DeLima M. Tumor necrosis factor during pregnancy and at the onset of labor and spontaneous abortion. Eur J Obstet Gynecol Reprod Biol 1999; 83:77-79.

Dejaco C, Angelberger S, Waldhoer T, et al. Risk factors for pregnancy outcome in patients with inflammatory bowel disease (IBD) Gastroenterology. 2006; 130(Suppl 2): A-39. (Abst)

Djokanovic N, Klieger-Grossmann C, Pupco A, Koren G. Safety of infliximab use during pregnancy. Reprod Toxicol 2011; 32:93-97.

Dolovich LR, Addis A, Vaillancourt JMR, Power JD, Koren G, EinarsonTR. Benzodiazepine use in pregnancy and major malformations or oral cleft: meta-analysis of cohort and case-controlled studies. BMJ 1998; 317:839-43.

Dominitz JA, Young JC, Boyko EJ. Outcomes of infants born to mothers with inflammatory bowel disease: a population-based cohort study. Am J Gastroenterol. 2002; 97:641-648

Falt A, Bengtsson T, Kennedy BM, Gyllenberg A, et al.Exposure of infants to budesonide through breast milk of asthmatic mothers.J Allergy Clinical Immunol 2007;120(4):798-802.

FDA 2010 Safety Labelling Changes Approved By FDA Center for Drug Evaluation and Research (CDER) - May 2010.

Ferguson BC, Mahsud-Dornan S, and Patterson RN Inflammatory bowel disease in pregnancy. BMJ. 2008; 337(7662): 170-173.

Fonager K, Sorensen HT, Olsen J, Dahlerup JF, Rasmussen SN. Pregnancy outcome for women with Crohn's disease: a follow-up study based on linkage between national registries. Am. J. Gastroenterol.1998; 93(12),:2426-2430 .

Francella A, Dyan A, Bodian C et al. Th e safety of 6-mercaptopurine for childbearing patients with inflammatory bowel disease: a retrospective cohort study . Gastroenterology 2003; $124: 9$ - 17 .

Gardiner SJ, Gearry RB, Roberts RL, et al. Exposure to thiopurine drugs through breast milk is low based on metabolite concentrations in mother-infant pairs. Br J Clin Pharmacol. 2006; 62: 453-456.

Gaudier FL, Santiago-Delpin E, Riveral J, et al.Pregnancy after renal transplantation.Surg Gynecol Obstet.1988;167(6):533-43.

Gin T. Propofol during pregnancy. Acta Anaesthesiol Sin 1994; 32:127-132.

Gisbert JP, Linares PM, McNicholl AG, et al. Meta-analysis: the efficacy of azathioprine and mercaptopurine in ulcerative colitis. AlimentPharmacol Ther. 2009; 30:126-137.

Golby M. Fertility after renal transplantation. Transplantation. 1970;10:201-207 
Goldstein LH, Dolinsky G, Greenberg R, et al. Pregnancy outcome of women exposed to azathioprine during pregnancy. Birth Defects Res A Clin Mol Teratol 2007; 79: 696-701.

Hernández-Díaz S, Mitchell AA, Kelley KE, Calafat AM, Hauser R. Medications as a potential source of exposure to phthalates in the U.S. population. Environ Health Perspect 2009; 117:185-189.

Ilnyckyji A, Blanchard JF, Rawsthorne P, Bernstein CN. Perianal Crohn's disease and pregnancy: role of the mode of delivery. Am J Gastroenterol 1999; 94:3274-3278.

Janneke van der Woude C, Sanja Kolacek Iris Dotan et al. European evidenced-based consensus on reproductionin inflammatory bowel disease.Journal of Crohn's and Colitis 2010;4:493-510

Jarnerot G, Fertility, sterility and pregnancy in chronic inflammatory bowel disease. Scand J Gastroenterol 1982; 17:1-4.

Kammerer WS.Non-obstetric surgery during pregnancy. Med Clin North am. 1979; 63:1157-64

Katz JA, Antoni C, Keenan GF, Smith DE, Jacobs SJ, Lichtenstein GR. Outcome of pregnancy in women receiving infliximab for the treatment of Crohn's disease and rheumatoid arthritis. Am J Gastroenterol. 2004; 99:2385-92

Khosla R, Willoughby CP, Jewell DP.Crohn's disease and pregnancy. Gut 1984; 25:52-56

Kornfeld D, Cnattingius S, Ekbom A. Pregnancy outcomes in women with inflammatory bowel disease--a population-based cohort study. Am J Obstet Gynecol 1997; 177:942-946.

Kwan L Y ,Mahadevan U. Inflammatory Bowel Disease and Pregnancy: An Update. Expert Rev Clin Immunol. 2010; 6(4):643-657

Laegreid L, Olegard R, Wahlstrom J, Conradi N. Teratogenic effects ofbenzodiazepine use during pregnancy. J Pediatr 1989; 114:126-31.

Lakatos PL, Szamosi T and Lakatos L. Smoking in inflammatory bowel diseases: good, bad or ugly? World J JGastroenterol. 2007; 13(46):6134-9.

Langagergaard V, Pedersen L, Gislum M, Norgard B, Sorensen HT. Birth outcome in women treated with azathioprine or mercaptopurine during pregnancy: Danish nationwide cohort study. Aliment Pharmacol Ther 2007; 25: 73-81.

Lichtiger S, Present DH, Kornbluth A, et al. Cyclosporine in Severe Ulcerative Colitis Refractory to Steroid Therapy. N Engl J Med 1994; 330:1841-1845

Ligumsky M, Badaan S, Lewis H et al. Eff ects of 6-mercaptopurinetreatment on sperm production and reproductive performance: a study inmale mice . Scand J Gastroenterol 2005; 40: 444 - 9.

Lin HC, Chiu CC, Chen SF et al. Ulcerative colitis and pregnancy outcomes in an Asian population. Am. J. Gastroenterol. 2010;105(2): 387-394

Lopez-Bernal, A, Flint, APF, Anderson, ABM, Turnbull, AC: 11 $\beta$-Hydroxysteroid dehydrogenase activity (E.C.1.1.1.146) in human placenta and decidua. J Steroid Biochem 1980 13:1081-1087,

Mahadevan U. Fertility and pregnancy in the patient with inflammatory bowel disease. Gut 2006;55:1198-1206.

Mahadevan U, Corley D. Aminosalicylates (ASA) use during pregnancy is not associated with increased adverse events or congenital malformations (CM) in women with inflammatory bowel disease (IBD). Gastroenterology 2006; 130(Suppl 2): A-40. (Abst)

Mahadevan U, Kane S. American gastroenterological association institute technical review on the use of gastrointestinal medications in pregnancy. Gastroenterology 2006; 131: 283-311.

Mahadevan U, Kane S, Sandborn WJ, et al. Intentional infliximab use during pregnancy for induction or maintenance of remission in Crohn's disease. Aliment Pharmacol Ther. 2005;21:733-38. 
Mahadevan U, Sandborn WJ, Li DK et al. Pregnancy outcomes in women with inflammatory bowel disease: a large community-based study from Northern California. Gastroenterology2007 133(4), 1106-1112

Marri SR, Ahn C, Buchman AL. Voluntary childlessness is increased in women with inflammatory bowel disease. Inflamm.Bowel Dis 2007;13(5): 591-599

Mercer BM, Merlino AA, Milluzzi CJ, Moore JJ. Small fetal size before 20 weeks' gestation: associations with maternal tobacco use, early preterm birth, and low birthweight. Am J Obstet Gynecol 2008; 198:673.

Mogadam M, Dobbins WO, Korelitz BI, et al. Pregnancy in inflammatory bowel disease: effect of sulfasalazine and corticosteroids on fetal outcome. Gastroenterology 1981; 80: 72-6.

Moretti ME, Verjee Z, Ito S, Koren G. Breast-feeding during maternal use of azathioprine. Ann Pharmacother 2006; 40:2269-2272.Moskovitz DN, Bodian C, Chapman ML, et al. The effect on the fetus of medications used to treat pregnant inflammatory bowel-disease patients. Am J Gastroenterol 2004; 99:656-6

Mottet C, Vader JP, Felley C, et al. Appropriate management of special situations in Crohn's disease (upper gastro-intestinal; extra-intestinal manifestations; drug safety during pregnancy and breastfeeding): Results of a multidisciplinary international expert panel-EPACT II. J Crohn's Colitis 2009; 3:257-263.

Mountifield R, Bampton P, Prosser R, Muller K, Andrews JM. Fear and fertility in inflammatory bowel disease: a mismatch of perception and reality affects family planning decisions. Inflamm Bowel Dis 2009; 15:720-725.

Mountifield RE, Prosser R, Bampton P, Muller K, Andrews JM. Pregnancy and IBD treatment: this challenging interplay from a patients' perspective. J Crohn's Colitis 2010; 4:176-182.

Murphy, BEP, Clark, SJ, Donald, IR, Pinsky, M, Vedady, DL: Conversion of maternal cortisol to cortisone during placental transfer to the human fetus. Am J Obstet Gynecol 1974 118:538-541.

Nagy S, Bush MC, Berkowitz R, Fishbein TM, Gomez-Lobo V. Pregnancy outcome in liver transplant recipients. Obstet Gynecol 2003;102:121-128.

Neissner M, Volk BA. Altered Th1/Th2 cytokine profiles in the intestinal mucosa of patients with inflammatory bowel disease as assessed by quantitative reversed transcribed polymerase chain reaction (RT-PCR) Clin Exp Immunol. 1995;101:428-35.

Norgard B, Fonager K, Pedersen L, Jacobsen BA, Sorensen HT. Birth outcome in women exposed to 5-aminosalicylic acid during pregnancy: a Danish cohort study. Gut 2003;52(2): 243-247.

Norgard B, Pedersen L, Christensen LA, Sorensen HT. Therapeutic drug use in women with Crohn's disease and birth outcomes: a Danish nationwide cohort study. Am J Gastroenterol 2007; 102: 1406-13.

Oresland T, Palmblad S, Ellstrom M et al. Gynaecological and sexual function related to anatomical changes in the female pelvis after restorative proctocolectomy. Int. J. Colorectal Dis. 1994;9(2), 77-81.

Orholm M, Binder V, Sørensen TI, Rasmussen LP, Kyvik KO. Concordance of inflammatory bowel disease among Danish twins. Results of a nationwide study. Scand J Gastroenterol. 2000;35:1075-81.

Ornoy A, Arnon J, Shechtman S, Moerman L, Lukashova I. Is benzodiazepine use during pregnancy really teratogenic? ReprodToxicol 1998;12:511-5.

Osei EK, Faulkner K.Fetal doses from radiological examinations. Br J Radiol. 1999 Aug;72(860):773-80. 
Ostensen M, Eigenmann GO. Etanercept in breast milk. J Rheumatol 2004;31:1017-1018.

Paediatric Formulary Committee. BNF for Children 2010. London: BMJ Publishing Group, RPS Publishing, and RCPCH Publications; 2010

Penn I, Makowski E, Droegemueller W, Halgrimson CG, Starzl TE. Parenthood in renal homograft recipients. JAMA. 1971; 216:1755-1761.

Pradat P, Robert-Gnansia E, Di Tanna GL, et al. First trimester exposure to corticosteroids and oral clefts. Birth Defects Res A Clin Mol Teratol 2003; 67:968-970.

Present DH. Pregnancy and inflammatory bowel disease. In: BaylessTM, HanauerSB, eds. Advanced Therapy of Inflammatory Bowel Disease. Hamilton: B.C. Decker Inc., 2001: 613-18.

Qureshi WA, Rajan E, Adler DG et al. ASGE guideline: guidelines for endoscopy in pregnant and lactating women. Gastrointest. Endosc. 2005; 61(3): 357-362.

Raatikainen K, Mustonen J, Pajala_M, Heikkinen M \& Heinonen S. The effects of pre- and post-pregnancy inflammatory bowel disease diagnosis on birth outcomes. Aliment Pharmacol Ther 2011; 33: 333-339

Kornfeld D, Cnattingius S, Ekbom A. Pregnancy outcomes in women with inflammatory bowel disease--a population-based cohort study. Am J Obstet Gynecol 1997; 177:942-946.

Rahimi R, Nikfar S, Rezaie A, Abdollahi M. Pregnancy outcome in women with inflammatory bowel disease following exposure to 5-aminosalicylic acid drugs: a meta-analysis. Reprod Toxicol 2008; 25:271-5.

Rajapakse RO, Korelitz BI , Zlatanic J et al. Outcome of pregnancies whenfathers are treated with 6-mercaptopurine for infl ammatory bowel disease .Am J Gastroenterol 2000 ; 95 : 684-8

Rosenkrantz JG, Githens JH, Cox SM, Kellum DL. Azathioprine (Imuran) and pregnancy. Am J Obstet Gynecol 1967; 97:387-394.

Roux $\mathrm{CH}$, Brocq O, Breuil V, Albert C, Euller-Ziegler L. Pregnancy in rheumatology patients exposed to anti-tumour necrosis factor (TNF)-alpha therapy. Rheumatology (Oxford) 2007; 46:695-698.

Sau A, Clarke S, Bass J, Kaiser A, Marinaki A, Nelson-Piercy C. Azathioprine and breastfeeding: is it safe? BJOG 2007; 114:498-501.

Shah NR ,Bracken MB.A systemic review and meta-analysis of prospective studies on the association betwe en cigarette smoking and preterm delivery.Am J Obtstet Gynecol $2000 ; 182: 465-72$.

Schnitzler F, Fidder H, Ferrante M, et al. Outcome of pregnancy in women with inflammatory bowel disease treated with antitumor necrosis factor therapy. Inflamm Bowel Dis 2011; 17:1846-1854.

Simpson PW, Melmed GY, Dubinksy M. The impact of medical therapy for inflammatory bowel disease on pregnancy outcome. Am J Gastroenterol. 2008; 103: 805-806

Skomsvoll JF, Wallenius M, Koksvik HS, et al. Drug insight: Anti-tumor necrosis factor therapy for inflammatory arthropathies during reproduction, pregnancy and lactation. Nat Clin Pract Rheumatol 2007; 3:156-164.

Steinlauf AF, Present DH. Medical management of the pregnant patient with inflammatory bowel disease. Gastroenterol Clin North Am. 2004; 33:361-85.

Stephens P, Nesbitt A, Foulkes R. Placental transfer of the anti-TNF antibody TN3 in rats: comparison of Immunoglobulin G1 and pegylated Fab versions. Gut 2006; 55:A8.Stewart, PM, Rogerson, FM, Mason, JI: Type 2, 11 B-hydroxysteroid dehydrogenase messenger RNA and activity in human placenta and fetal membranes: its relationship to birth weight and putative role in fetal steroidogenesis. J Clin Endocrinol Metab 1995; 80:885-890, 
Subhani JM, Hamiliton MI. Review article: The management of inflammatory bowel disease during pregnancy. Aliment Pharmacol Ther. 1998; 12:1039-1053.

Teahon K,Pearson M,Levi AJ,Bjarnson I.Elemental diet in the management of Crohn's disease during pregnancy.Gut.1991;32(9):1079-1081

Truel C, Lopez-San Roman A,Bermejo F, Taxonera C et al. Outcomes of pregnancies fathered by inflammatory bowel disease patients exposed to thiopurine. Am J Gastroenterol.2010; 105(9):2003-8.

Thompson N, Driscoll R, Pounder RE, et al. Genetics versus environment in inflammatory bowel disease. Br Med J 1996; 312: 95-6.

Tysk C, Lindberg E, Järnerot G, Flodérus-Myrhed B. Ulcerative colitis and Crohn's disease in an unselected population of monozygotic and dizygotic twins. A study of heritability and the influence of smoking. Gut. 1988; 29:990-6.

Valentin J, Editor, Annals of the ICRP, Publication 84: Pregnancy and Medical Radiation, International Commission on Radiological Protection, Volume 30, No. 1. Tarrytown, New York: Pergamon, Elsevier Science, Inc., 2000.

Van Assche G, Dignass A, Reinisch W, et al. The second European evidence based Consensus on the diagnosis and management of Crohn's disease: special situations. J Crohns Colitis 2010; 4: 63-101.

van der Woude CJ, Kolacek S, Dotan I, Oresland T, Vermeire S, Munkholm P, Mahadevan U, Mackillop L, Dignass A; European Crohn's Colitis Organisation (ECCO). European evidenced-based consensus on reproduction in inflammatory bowel disease. J Crohns Colitis. 2010 Nov;4(5):493-510

Van Domselaar M, Algaba A, Estellés J, López-Serrano P, Linares PM, Muriel A. Outcomes of pregnancies fathered by inflammatory bowel disease patients exposed to thiopurines. Am J Gastroenterol. 2010 Sep; 105(9):2003-8

Vasiliauskas EA, Church JA, Silverman N, Barry M, Targan SR, Dubinsky MC. Case report: evidence for transplacental transfer of maternally administered infliximab to the newborn. Clin Gastroenterol Hepatol 2006; 4:1255-1258.

Waljee J, Morris AM, Higgins PD. Threefold increased risk of infertility: a meta-analysis of infertility after ileal pouch anal anastomosis in ulcerative colitis. Gut 55(11), 15751580 (2006).

Wolf D MU. Certolizumab Pegol Use in Pregnancy: Low Levels Detected in Cord Blood. Arthritis Rheum 2010; 62:718.

Yang H, McElree C, Roth MP, Shanahan F, Targan SR, Rotter JI. Familial empirical risks for inflammatory bowel disease: Differences between Jews and non-Jews. Gut. 1993;34:517-24.

Yu XW, Li X, Ren YH, Li XC. Tumour necrosis factor-alpha receptor 1 polymorphisms and serum soluble TNFR1 in early spontaneous miscarriage. Cell Biol Int 2007;31:1396-1399.

Zimm S, Collins JM, Riccardi R, O'Neill D, Narang PK, Chabner B, Poplack DG. Variable bioavailability of oral mercaptopurine.Is maintenance chemotherapy in acute lymphoblastic leukemia being optimally delivered? N Engl J Med. 1983; 308:1005-1009.

Zlatanic J, Korelitz BI, Rajapakse R, et al. Complications of pregnancy and child development after cessation of treatment with 6-mercaptopurine for inflammatory bowel disease. J Clin Gastroenterol. 2003; 36: 303-309. 


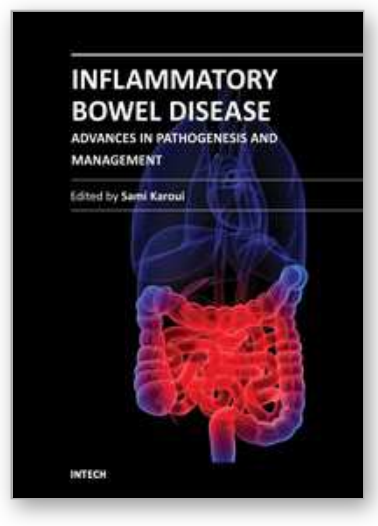

\author{
Inflammatory Bowel Disease - Advances in Pathogenesis and \\ Management \\ Edited by Dr. Sami Karoui
}

ISBN 978-953-307-891-5

Hard cover, 332 pages

Publisher InTech

Published online 27, January, 2012

Published in print edition January, 2012

This book is dedicated to inflammatory bowel disease, and the authors discuss the advances in the pathogenesis of inflammatory bowel disease, as well as several new parameters involved in the etiopathogeny of Crohn's disease and ulcerative colitis, such as intestinal barrier dysfunction and the roles of TH 17 cells and IL 17 in the immune response in inflammatory bowel disease. The book also focuses on several relevant clinical points, such as pregnancy during inflammatory bowel disease and the health-related quality of life as an end point of the different treatments of the diseases. Finally, advances in management of patients with inflammatory bowel disease are discussed, especially in a complete review of the recent literature.

\title{
How to reference
}

In order to correctly reference this scholarly work, feel free to copy and paste the following:

Flavio M. Habal (2012). Approach to the Management of the Pregnant Inflammatory Bowel Disease Patient: Successful Outcome, Inflammatory Bowel Disease - Advances in Pathogenesis and Management, Dr. Sami Karoui (Ed.), ISBN: 978-953-307-891-5, InTech, Available from:

http://www.intechopen.com/books/inflammatory-bowel-disease-advances-in-pathogenesis-andmanagement/inflammatory-bowel-disease-in-pregnancy-clinical-outcome-and-management

\section{INTECH}

open science | open minds

\section{InTech Europe}

University Campus STeP Ri

Slavka Krautzeka 83/A

51000 Rijeka, Croatia

Phone: +385 (51) 770447

Fax: +385 (51) 686166

www.intechopen.com

\section{InTech China}

Unit 405, Office Block, Hotel Equatorial Shanghai

No.65, Yan An Road (West), Shanghai, 200040, China

中国上海市延安西路65号上海国际贵都大饭店办公楼405单元

Phone: +86-21-62489820

Fax: +86-21-62489821 
(C) 2012 The Author(s). Licensee IntechOpen. This is an open access article distributed under the terms of the Creative Commons Attribution 3.0 License, which permits unrestricted use, distribution, and reproduction in any medium, provided the original work is properly cited. 